\title{
The haptic oblique effect in the perception of rod orientation by blind adults
}

\author{
EDOUARD GENTAZ and YVETTE HATWELL \\ Université Pierre Mendès France, Grenoble, France
}

\begin{abstract}
The haptic perception of vertical, horizontal, $+45^{\circ}$ oblique, and $+135^{\circ}$ oblique orientations was studied in completely blind adults. The purpose was to determine whether the variations of the gravitational cues provided by the arm-hand system during scanning would affect the manifestation of the oblique effect (lower performance in oblique orientations than in vertical-horizontal ones) as they did in blindfolded sighted people (Gentaz \& Hatwell, 1996). In blindfolded sighted adults, the oblique effect was reduced or absent when the magnitude of gravitational cues was decreased. If visual experience participated in the haptic oblique effect, we should observe no oblique effect in early blind subjects in the conditions of manual exploration where late blind and blindfolded sighted manifest this effect. The magnitude of gravitational cues was therefore varied by changing gravity constraints, whereas the variability of these cues was varied by changing the plane in which the task was performed: horizontal (low variability) and frontal (high variability). Early and late blind adults were asked to explore haptically a rod and then to reproduce its orientation ipsilaterally in one of two exploratory conditions in each plane. In the horizontal plane, the oblique effect was absent, whatever the gravity constraints, in both groups (early and late blind subjects). In the frontal plane, the oblique effect was present, whatever the gravity constraints, in both groups. Taken together, these results showed that, in blind people, the variability of gravitational cues played a role in the haptic oblique effect; no effect of previous visual experience was observed.
\end{abstract}

The problem studied here is how totally blind adults perceive vertical, horizontal, $+45^{\circ}$ oblique, and $+135^{\circ}$ oblique orientations of a rod in the haptic (tactualkinesthetic) modality. We were interested in examining this spatial property because previous research had shown that the modes of coding orientation may differ according to the perceptual modality. In vision, the vertical and horizontal orientations are always coded more accurately than the oblique orientations. This anisotropy, which Appelle (1972) called the oblique effect, has been found in a wide variety of perceptual tasks (Bryant, 1974; Chen \& Levi, 1996; Corballis \& Beale, 1976; Dick \& Hochstein, 1989; Essock, 1980, 1990; Heeley \& Timmey, 1988; Howard, 1982; Jenkins, 1985; Long \& Tuck, 1991; Pointer, 1996; Ross, 1992; Saarinen \& Levi, 1995; Vogels \& Orban, 1985). By contrast, in the haptic modality, the oblique effect has been studied less often, and in blindfolded sighted people, its presence or absence has been found to vary according to the conditions of manual exploration (Appelle \& Countryman, 1986; Gentaz \& Hatwell, 1994, $1995,1996 \mathrm{a}, 1996 \mathrm{~b})$. Our present aim was to establish

\footnotetext{
This work was supported by grants from the Universite Pierre Mendès France of Grenoble and from the Centre National de la Recherche Scientifique. We thank Lester Krueger and two anonymous reviewers for their helpful comments on an earlier version of this manuscript. Correspondence and requests for reprints should be sent to E. Gentaz or Y. Hatwell, Laboratoire de Psychologie Expérimentale, Université Pierre Mendès France, P.O. Box 47, 38040 Grenoble Cedex 9, France (e-mail: edouard.gentaz@upmf-grenoble.fr).
}

whether the same variations would be observed in completely blind adults.

The presence of an oblique effect reveals a spatial coding relative to a frame, because obliques are obliques only through reference to some spatial frame. Classically, a distinction was made between an egocentric frame (with reference to the subject's body) and an allocentric frame (with reference to external cues). Both frames are available in touch and in vision (Hermelin \& O'Connor, 1971; Rieser \& Pick, 1976). Paillard (1991; see Berthoz, 1991) further proposed that the egocentric and allocentric frames depend on a geocentric frame based on the direction of gravity and defining a Cartesian coordinate system with vertical and horizontal coordinate axes. In the frontal plane, coding of the vertical and horizontal orientations requires processing only one of the coordinate axes. Oblique orientations require a coding taking into account both axes (Cecala \& Garner, 1986; Lasaga \& Garner, 1983) and integrating the parameters computed on each one. The difference between these two modes of coding would largely explain the oblique effect.

It should be noted that the oblique effect occurs independently of the rate of global errors. This means that it may be present in relatively accurate performances as well as in poor ones, because it results from the difference between the responses to the vertical and horizontal orientations on the one hand, and the responses to the oblique ones on the other.

The interpretation of an absence of the haptic oblique effect is more difficult. On the one hand, this absence may mean that the mode of coding was spatial but that 
the available cues were too poor to generate a difference between vertical and horizontal settings in comparison with oblique ones. On the other hand, the $+45^{\circ}$ and $+135^{\circ}$ obliques may be other dominant orientations (Stivalet, Marendaz, Barraclough, \& Mourareau, 1995; Yakimoff, Lánský, Mitrani, \& Radil, 1989), acting themselves as coordinate axes. Finally, the absence of the oblique effect may also result from movement coding (e.g., coding the parameters of joint angles during scanning). As stated earlier, an oblique needs to be specified relative to both vertical and horizontal axes, and these coordinated reference axes are more difficult to process if orientations are coded in terms of sequentially organized movements (for a review, see Millar, 1994). It is noteworthy that movement coding was also observed in prior research on the haptic perception of distance (Lederman, Klatzky, \& Barber, 1985) and on the accuracy of spatial pointing toward proprioceptive targets (Rossetti, Gaunet, \& Thinus-Blanc, 1996; Rossetti \& Régnier, 1995).

Let us summarize the empirical data available on the haptic perception of orientation of blindfolded sighted people. A haptic oblique effect was found by Lechelt, Eliuk, and Tanne (1976) and Lechelt and Verenka (1980). According to Lechelt et al. (1976; Lechelt \& Verenka, 1980), these results revealed the importance of experiential and learning factors: because verticals and horizontals are privileged in our "carpentered" environment, the same oblique effect is at work in vision and haptics. But Appelle and Countryman (1986) questioned this interpretation. They argued that the haptic oblique effect demonstrated by Lechelt et al. (1976; Lechelt \& Verenka, 1980) stemmed from the inherently different scanning patterns required in the exploration of obliques when one hand explored the standard and the other hand set the response rod ("contralateral condition"), as was the case in Lechelt's experiments. This assumption was supported by the fact that Appelle and Countryman found no haptic oblique effect in an "ipsilateral condition" in which the same hand explored and set the standard and response rod.

However, these studies did not control the plane in which the task was performed. Gentaz and Hatwell (1995) asked blindfolded subjects to reproduce the orientation of a rod, in the ipsilateral and contralateral conditions, either in the horizontal plane (like the surface of a table, as in Appelle \& Countryman, 1986), or in the frontal plane (like the surface of a blackboard on a wall, as in Lechelt et al., 1976, and Lechelt \& Verenka, 1980), or in the sagittal plane (in the median plane passing through the midline of the subject's head). In the latter plane, the same patterns of agonist/antagonist muscles and tendons are activated when one hand explores the vertical, horizontal, and oblique rods and the other hand reproduces these orientations. By contrast, in the horizontal and frontal planes, different patterns of agonist/antagonist muscles and tendons are activated when one hand explores an oblique and the other hand reproduces this oblique. However, the haptic oblique effect was present in this sagittal plane, even when the same hand explored and set the response rod (Gentaz \& Hatwell, 1995). Therefore, these results did not support Appelle and Countryman's interpretation.

Recently, Gentaz and Hatwell (1996b) showed that the gravitational cues provided by the antigravitational forces developed by the scanning arm-hand system were involved in the haptic oblique effect, because these cues specify one axis of reference, the gravity direction. Gravitational cues are indirect cues taken from the proprioceptive information contained in the pattern of tissue deformations (skin mechanoreceptors, joints, and muscles). These deformations depend on the specific muscular forces necessary to maintain and move the arm-hand system under gravity environment $(G)$ during perceptual exploration (Gentaz \& Hatwell, 1996b; for possible physiological explanations, see Dietz, 1994). The magnitude of these gravitational cues varies according to the plane in which the task is performed. In the frontal and sagittal planes, antigravitational forces are not the same in the different directions of exploration: The bottom-up direction requires high muscular antigravitational forces, whereas the reverse direction requires lower muscular effort. By contrast, in the horizontal plane, the variability of antigravitational forces (and therefore of the gravitational cues that they generate) is minimal: Because the subject's movements are performed in front of the subject in a direction perpendicular to gravity, they require constant antigravitational forces.

Gentaz and Hatwell (1996b) modified gravity constraints by testing blindfolded adults, in the horizontal plane, either with the forearm resting on the disk surface supporting the rod ("supported forearm" condition), which was similar to the condition tested by Appelle and Countryman (1986) and Gentaz and Hatwell (1995), or with the forearm unsupported in the air. In the latter case, greater antigravitational forces were elicited during scanning. The oblique effect was present in the "unsupported forearm" condition and absent in the "supported forearm" condition. Another experiment tested the three planes, either in a "natural" ("unsupported forearm") condition or in a "lightened forearm" condition in which the gravitational cues were reduced by lightening the subject's forearm (through a device consisting of a set of weights and pulleys). The magnitude of the oblique effect was lower in the "lightened" condition than in the "natural" one, and there was no effect of the plane.

The aim of the present research was to extend these experiments to completely blind subjects. In blindfolded sighted subjects, haptic spatial functioning is systematically influenced by visual representations because of the dominant function of vision in human spatial processing (for reviews, see Hatwell, 1978, 1985, 1990, 1994; Heller \& Schiff, 1991; Millar, 1994). Visual recoding of haptic spatial information has been demonstrated in shape recognition and reconstruction (Worchel, 1951), in spatial localization (Pick, 1974), in the vertical-horizontal illusion (Heller, 1991; Heller \& Joyner, 1993), in the hap- 
tic judgment of orientation (Appelle \& Countryman, 1986; Appelle \& Gravetter, 1985), in tactual picture identification (Heller, Calcaterra, Burson, \& Tyler, 1996), and in the production of drawings of objects at a slant (Heller, Calcaterra, Tyler, \& Burson, 1996). Therefore, the comparison of the haptic oblique effect in early blind, late blind, and blindfolded sighted people should allow an evaluation of the role of visual experience in its manifestation. In the two latter populations, the haptic modality has been or is coordinated with the visual modality, whereas in the former one, it is not. On the other hand, because blind people are highly trained in haptics, they may rely on specific haptic perceptual cues modifying the relative difficulty of the different orientations tested. This means that two factors act in different directions: $\mathrm{Vi}$ sual representations and visual recoding may induce similar patterns of results in blindfolded sighted and late blind people, whereas intensive training in haptics may induce different patterns of results in early blind people.

The available data on the effect of visual experience on the haptic spatial abilities of the blind concern mainly global performances and are not consistent. Some researchers have found poorer spatial performances in early blind subjects, whereas others have found no difference between early blind, late blind, and blindfolded sighted subjects. A main factor explaining these results seems to be the nature of the spatial task (for recent reviews, see Klatzky, Golledge, Loomis, Cicinelli, \& Pellegrino, 1995; Thinus-Blanc \& Gaunet, 1997). Generally, the performances of early blind subjects are inferior to those of late blind subjects in locomotor and tabletop tasks that require mental reorganization of spatial information, such as shape construction problems, mental rotation, and spatial inferences. By contrast, there is no difference between early blind and late blind subjects in the tabletop tasks involving simple reproduction of previously acquired spatial information, such as recognition tasks.

As stated earlier, the oblique effect does not concern global performances (high or low accuracy of judgments on orientation) but rather the difference between responses as a function of the orientations tested: verticalhorizontal versus oblique ones. In the blind, the only research studying this oblique effect in the perception of the orientation of a line was done by Lechelt (1988), who observed in the passive tactile modality an oblique effect in 5 totally blind adults tested with an electrotactile cutaneous stimulation (obtained via the Optacon apparatus, which is a reading aid for the blind). However, only 2 subjects were blind from birth. Other experiments studied the effect of orientation on tactual pattern recognition - for example, on passive identification of individual numerals or number sequences printed on the palm or active identification of standard letters printed in braille. They showed that orientation had a general effect on the recognition of these tactual patterns. Performances were lower on tilted patterns, and there was an interaction between this effect and visual status (Heller, 1987, 1989, 1992; for a review, see Millar, 1994). Thus, Heller (1989) showed that early blind subjects were strongly influenced by orientation, with poorer performance on these rotated patterns, whereas the performance of sighted and late blind subjects was not altered. In addition, Heller (1992) showed that the effect of tilt on braille identification for both early and late blind subjects was significant, although this effect was lower than in the blindfolded sighted subjects.

When active touch was used in these studies, however, the subjects performed only finger movements to explore the small patterns used as stimuli (e.g., braille). Therefore, the arm-hand system was not activated as it was in the experiments reported above in which the haptic oblique effect was studied in blindfolded sighted subjects scanning large bars. Contrary to finger movements, shoulder and arm movements are highly constrained by the gravity environment (Martinez, 1971; Paillard, 1991).

In the present research, we therefore tested a group of early blind and a group of late blind subjects with a device allowing the measurement of the haptic oblique effect under changed gravity constraints. We reproduced the experimental conditions reported by Gentaz and Hatwell (1996b), in which the magnitude and the variability of the gravitational cues provided during the scanning of a large bar $(25 \mathrm{~cm})$ were varied. The magnitude was manipulated by varying gravity constraints, either natural or reduced, and changes in the variability of these cues were obtained by having the task performed in two planes: horizontal (low variability) or frontal (high variability). Our aim was to determine whether the pattern of results observed in the blind would be different from the pattern found by Gentaz and Hatwell (1996b) in blindfolded sighted people. Visual spatial representations may act on the haptic coding of the vertical orientation because the somesthetic gravitational cues have been correlated with the visual cues indicating verticality (such as the walls of the room, etc.). However, if Klatzky et al.'s (1995) and Thinus-Blanc and Gaunet's (1997) proposition concerning the role of task was valid, one should observe no difference between early and late blind subjects, because the task in the present research involved a single reproduction of previously acquired information.

We asked early and late blind adults to explore haptically a rod and then to reproduce its orientation ipsilaterally. There were two tasks in which gravity constraints were varied in addition to a variation of the plane in which the task was performed. In Task A, the rod was presented in the horizontal plane and the distance between this rod and the metal disk on which it was fixed was either $0 \mathrm{~cm}$ (supported forearm condition) or $8 \mathrm{~cm}$ (unsupported forearm condition). In the supported forearm condition, the magnitude of gravitational cues was minimal and stemmed only from the reaction forces of the disk. By contrast, in the unsupported forearm condition, antigravitational forces were necessarily elicited when subjects explored the rod. In Task B, the rod was presented in the frontal plane and it was $8 \mathrm{~cm}$ distant 
from the metal disk. The gravitational cues were either natural or reduced by lightening the subject's forearm through a device consisting of a set of weights and pulleys.

The question was whether this blind population would manifest the same patterns of results as those observed by Gentaz and Hatwell (1996b) in blindfolded sighted adults. In the latter population, the haptic oblique effect was absent in the supported forearm condition of Task A (horizontal plane), whereas it was present in the unsupported forearm condition of this task. In Task B (frontal plane), the oblique effect was present in both forearm conditions, but its magnitude was reduced when fewer gravitational cues were available in the lightened forearm condition. If visual experience was not involved in these results, early and late blind adults would manifest the same pattern of results as would these blindfolded sighted adults. By contrast, if this pattern and, more generally, the haptic oblique effect was in some way dependent on visual experience, no oblique effect (in either task or condition) should be observed in the early blind subjects, whereas this effect would be present in the late blind subjects in the same tasks and the same conditions as those for blindfolded sighted ones.

\section{METHOD}

\section{Subjects}

The subjects were 12 early blind adults and 12 late blind adults recruited at Industries of the Blind workshops in the communities of Lyon and Grenoble. All blind subjects had attended some college. Their ages ranged from 24 to 56 years. None of the subjects having light perception could discriminate shape or hand movements. The early blind subjects were blind at birth (or when removed from incubators, in the case of the retrolental fibroplasia subjects). Blindness had begun in the late blind subjects after the age of 4 years (mean age of loss of sight, 16.4). Table 1 shows the characteristics of these blind subjects.

\section{Apparatus}

The apparatus was composed of a black metal disk (diameter $40 \mathrm{~cm})$ equipped with a rod $(25 \times 1.8 \mathrm{~cm})$. This rod was mounted above the center of the disk and could be rotated $360^{\circ}$ around its central axis. Magnets were fixed inside the rod to maintain it in the desired orientation and to prevent involuntary deviation from its position during haptic scanning. The rod was connected with a potentiometer which indicated (in degrees) to what extent its orientation deviated from the vertical. To test the two planes of space, the disk and rod could be positioned either in the horizontal plane (like the surface of a table), or in the frontal plane (like the surface of a blackboard). The two planes were orthogonal.

Task $A$ was performed in the horizontal plane. In it, the rod could be fixed either directly in contact with the disk surface supporting it (Figure 1A), or parallel to the disk surface at $8 \mathrm{~cm}$ from it (Figure IB). The vertical orientation was arbitrarily defined as aligned with the subjects' midsagittal plane. The disk was centered on the subject's body midline. The subjects sat in the front midline of the apparatus and were asked to maintain their trunk fixed upright.

Task B was performed in the frontal plane. In it, the apparatus had the rod $8 \mathrm{~cm}$ distant from the disk surface. The lightening mechanism was composed of a strap tied up to the subject's forearm. This strap was connected with a weight suspended by a cable and sliding through two fixed pulleys (Figure 2).

\section{Experimental Conditions and Procedure}

The subject was taken individually into a quiet room. In both tasks, the subject was asked to scan haptically with one hand (i.e., to move actively the arm-hand-digit system) on the oriented standard rod and to reproduce the same orientation with the same hand after a 5-sec delay. A 5-sec delay was introduced to replicate Gentaz and Hatwell's $(1995,1996 \mathrm{~b})$ procedures. Because the same rod was alternately the standard and the response rod, this delay was also used by the experimenter to modify the orientation of the rod between the presentation and the response phases. The initial orientation of the response rod was approximately $80^{\circ}$ more or less than the standard orientation tested during the trial and was determined at random by the experimenter at the right or the left of the standard orientation. During the delay, the subject was asked to move her/his hand off the device and to maintain it in contact with her/his abdomen.

The subjects haptically explored the standard with one hand over its full length. After the delay, using the same hand, they set the response rod. Each subject performed both Task A (horizontal plane) and Task B (frontal plane). The order of presentation of these tasks was counterbalanced across subjects.

In Task A (horizontal plane), each subject was tested under one of two exploratory conditions. In the first, or supported forearm, condition, the rod was in direct contact with the disk surface. The subject was instructed to maintain his/her wrist and forearm resting in physical contact with the disk support during the whole trial. In a familiarization phase, the arm-hand system was first guided by

Table 1

Characteristics of the Blind Subjects, Including Gender, Age, Presence of Light Perception, Cause of Blindness, and Age of Onset

\begin{tabular}{|c|c|c|c|c|c|c|c|}
\hline \multicolumn{4}{|c|}{ Early Blind } & \multicolumn{4}{|r|}{ Late Blind } \\
\hline Gender & Age & LP & Cause & Gender & Age & LP & Cause (and Age of Onset) \\
\hline M & 39 & $\mathrm{~N}$ & Early meningitis & M & 43 & $\mathrm{~N}$ & Retinal detachment (31) \\
\hline M & 27 & $\mathrm{~N}$ & Glaucoma & M & 36 & $\mathrm{~N}$ & Trauma (16) \\
\hline M & 36 & $\mathrm{Y}$ & Rubella & M & 46 & $\mathrm{~N}$ & Trauma (19) \\
\hline $\mathrm{M}$ & 36 & $\mathrm{~N}$ & Retrolental fibroplasia & $\mathrm{F}$ & 54 & $\mathrm{~N}$ & Retinitis pigmentosa (19) \\
\hline $\mathrm{F}$ & 40 & $\mathrm{Y}$ & Glaucoma & M & 24 & $\mathrm{~N}$ & Glaucoma (5) \\
\hline $\mathrm{F}$ & 38 & $\mathrm{~N}$ & Glaucoma & $\mathrm{F}$ & 55 & $\mathrm{~N}$ & Cataracts $(37)$ \\
\hline $\mathrm{M}$ & 40 & $\mathrm{~N}$ & Glaucoma & $\mathrm{F}$ & 25 & $\mathrm{~N}$ & Enucleation (7) \\
\hline F & 38 & $\mathrm{~N}$ & Rubella & $\mathrm{M}$ & 32 & $\mathrm{~N}$ & Trauma (5) \\
\hline $\mathbf{F}$ & 25 & $\mathrm{~N}$ & Microphtalmy & $\mathrm{F}$ & 39 & $\mathrm{~N}$ & Facial angioma (12) \\
\hline $\mathrm{M}$ & 34 & $\mathrm{Y}$ & Glaucoma & $\mathrm{M}$ & 45 & $\mathrm{~N}$ & Meningitis (18) \\
\hline M & 46 & $\mathrm{~N}$ & Glaucoma & $\mathrm{M}$ & 35 & $\mathrm{Y}$ & Optic nerve atrophy after cerebral tumor (8) \\
\hline M & 25 & $\mathrm{Y}$ & Retrolental fibroplasia & $\mathrm{M}$ & 56 & $\mathrm{~N}$ & Retinal detachment (20) \\
\hline
\end{tabular}

Note-All blind subjects had attended some college. LP, light perception. Mean age of early blind subjects, 35.3 years; mean age of late biind subjects, 40.8 years; mean age of loss of vision of the late blind subjects, 16.4 years. 


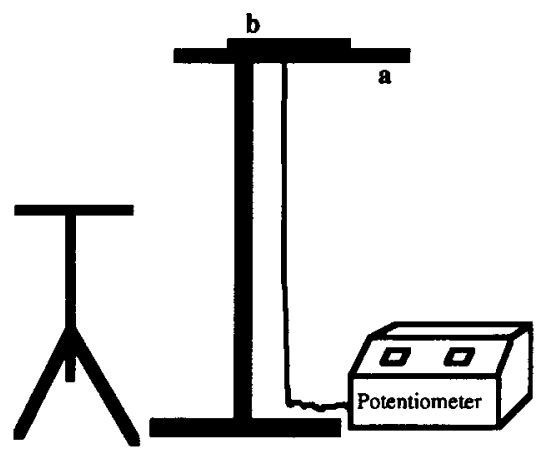

$\mathbf{A}$

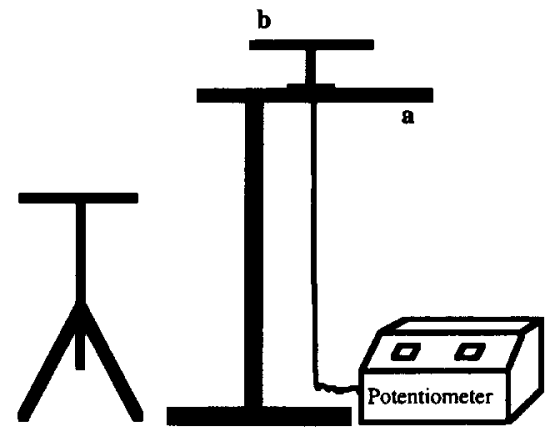

B

Figure 1. Lateral view of the apparatus, with the disk positioned in the horizontal plane and the rod fixed $(A)$ directly in contact with the disk or (B) $8 \mathrm{~cm}$ distant from the disk (a, disk; b, stimulus rod).

the experimenter and the subject was trained to explore actively under these instructions. In the second, or unsupported forearm, condition, the subjects explored a rod $8 \mathrm{~cm}$ distant from the disk surface and parallel to it.

In Task B (frontal plane), each subject was tested under one of two forearm conditions. In the natural condition, the subjects were not connected to the lightening device and they explored the rod naturally. This condition was similar to the unsupported forearm condition used in Task $\mathrm{A}$ in the horizontal plane. In the lightened forearm condition, the subjects were connected to the pulleys and they explored the rod with their forearm lightened. In order to find the appropriate weight for each subject, the experimenter tested different weights (in ascending and descending series, by steps of $10 \mathrm{~g}$ of sand) and asked the subject to indicate the weight "with which his/her arm did not feel any pressure pulling it upward or downward" when the forearm was at the level of the center of the disk (Figure 2). This weight was selected as the most appropriate to unweight the subject's arm. Of course, these appropriate weights depended on the subject's body characteristics (size and weight). The mean selected weight was $780 \mathrm{~g}$ (range, $750-850 \mathrm{~g}$ ).

In addition, the experimental design was planned so that each subject was tested once with natural gravitational cues (unsupported forearm condition of Task A or natural condition of Task B) and once with reduced gravitational cues (supported forearm condition of Task A or lightened forearm condition of Task B), in a counterbalanced order. Finally, for each exploratory condition, half of the subjects used their right hand and the other half used their left hand.

Four orientations were tested in each task: $0^{\circ}$ (vertical aligned with the subject's midsagittal plane in the horizontal plane and with the gravitational axis in the frontal plane), $+45^{\circ}$ (left-slanting oblique in relation to the subject's view), $+90^{\circ}$ (horizontal, perpendicular to the subject's sagittal plane), and $+135^{\circ}$ (right-slanting oblique in relation to the subject's view). Additional catch trials in other orientations (randomly selected among the following: $+15^{\circ}$, $+75^{\circ},+105^{\circ}$, or $+165^{\circ}$ ) were interspersed with test trials in order to avoid awareness that the tested orientations were restricted to four. Each subject performed 3 trials in each of the four orientations and in each of the two tasks (planes; i.e., 24 test trials per subject). In addition, 6 catch trials were presented randomly ( 3 in each task). Therefore, there were 30 trials per subject. No feedback was given to the subject during the experiment, and there was no time constraint.

\section{RESULTS}

Data analyses were carried out on the angular difference (in degrees) between the positions of the standard and test rods. The mean error (signed and absolute) was then calculated for each of the four orientations for each subject.

The mean signed errors for each condition are shown in Table 2. We considered that the four orientations moved counterclockwise across an imaginary circle (starting from the vertical orientation), and we attributed to the subject's response a positive sign if there was an overestimation (the response rod was positioned too far counterclockwise from the standard) and a negative sign if there was an underestimation. For instance, for the $+45^{\circ}$ standard, a $+46^{\circ}$ response was "too far" in the positive direction (overestimation), whereas a $+43^{\circ}$ response was "not far enough" in the negative direction (underestimation). A

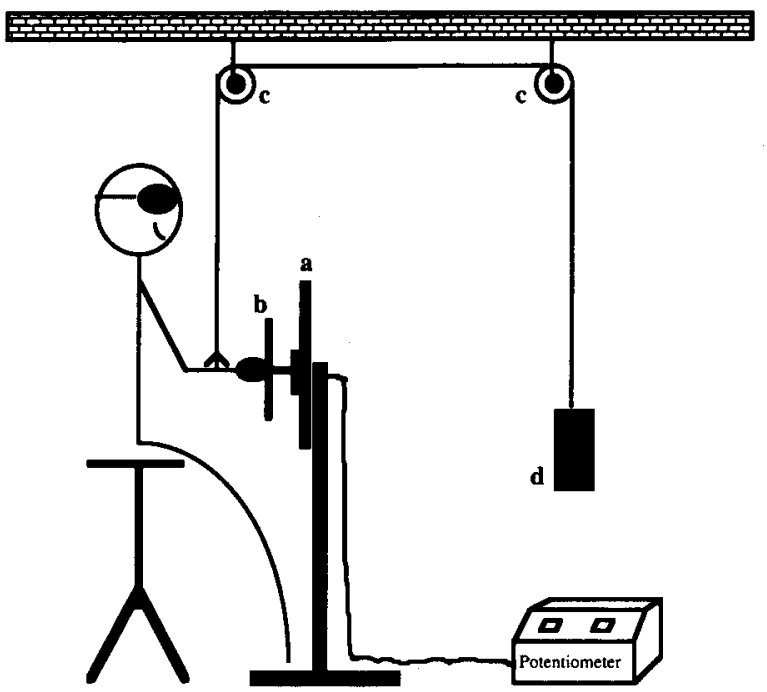

Figure 2. Apparatus showing how the subject's forearm was lightened in the frontal plane (a, disk; b, stimulus rod; c, pulleys; d, weighted block). 
Table 2

Mean Signed Angular Errors ( $M$, in Degrees), Standard Deviations of Means ( $S D)$, and Tests of Significance $(t)$ as a Function of Plane, Visual Status, Forearm Condition, and Stimulus Orientation

\begin{tabular}{|c|c|c|c|c|c|c|c|c|c|}
\hline \multirow[b]{3}{*}{ Visual Status } & \multirow[b]{3}{*}{ Forearm } & \multicolumn{8}{|c|}{ Orientation } \\
\hline & & \multicolumn{2}{|c|}{ Vertical } & \multicolumn{2}{|c|}{$+45^{\circ}$} & \multicolumn{2}{|c|}{ Horizontal } & \multicolumn{2}{|c|}{$+135^{\circ}$} \\
\hline & & $M$ & $S D$ & $M$ & $S D$ & $M$ & $S D$ & $M$ & $S D$ \\
\hline \multicolumn{10}{|c|}{ Task A: Horizontal Plane } \\
\hline Early blind & $\begin{array}{l}\text { Unsupported } \\
\text { Supported }\end{array}$ & $\begin{array}{l}3.3^{\circ} \\
3.4^{\circ}\end{array}$ & $\begin{array}{l}5.6^{\circ} \\
9.1^{\circ}\end{array}$ & $\begin{array}{l}-4.9^{\circ} \\
-2.2^{\circ}\end{array}$ & $\begin{array}{r}7.3^{\circ} \\
10.0^{\circ}\end{array}$ & $\begin{array}{l}4.2^{\circ *} \\
5.9^{\circ}\end{array}$ & $\begin{array}{l}3.6^{\circ} \\
8.3^{\circ}\end{array}$ & $\begin{array}{l}1.4^{\circ} \\
5.3^{\circ}\end{array}$ & $\begin{array}{l}5.6^{\circ} \\
7.3^{\circ}\end{array}$ \\
\hline Late blind & $\begin{array}{l}\text { Unsupported } \\
\text { Supported }\end{array}$ & $\begin{array}{l}3.5^{\circ} \\
1.9^{\circ}\end{array}$ & $\begin{array}{l}8.3^{\circ} \\
3.3^{\circ}\end{array}$ & $\begin{array}{l}1.4^{\circ} \\
3.2^{\circ}\end{array}$ & $\begin{array}{l}10.5^{\circ} \\
10.4^{\circ}\end{array}$ & $\begin{array}{l}0.3^{\circ} \\
3.6^{\circ}\end{array}$ & $\begin{array}{l}7.6^{\circ} \\
8.7^{\circ}\end{array}$ & $\begin{array}{r}-1.9^{\circ} \\
3.3^{\circ}\end{array}$ & $\begin{array}{r}12.1^{\circ} \\
7.6^{\circ}\end{array}$ \\
\hline \multicolumn{10}{|c|}{ Task B: Frontal Plane } \\
\hline Early blind & $\begin{array}{l}\text { Natural } \\
\text { Lightened }\end{array}$ & $\begin{array}{r}-1.5^{\circ} \\
2.2^{\circ}\end{array}$ & $\begin{array}{l}4.6^{\circ} \\
4.0^{\circ}\end{array}$ & $\begin{array}{l}1.8^{\circ} \\
2.0^{\circ}\end{array}$ & $\begin{array}{r}4.1^{\circ} \\
11.8^{\circ}\end{array}$ & $\begin{array}{l}0.0^{\circ} \\
0.6^{\circ}\end{array}$ & $\begin{array}{l}4.3^{\circ} \\
7.9^{\circ}\end{array}$ & $\begin{array}{l}-5.6^{\circ} \dagger \\
-4.0^{\circ}\end{array}$ & $\begin{array}{l}6.6^{\circ} \\
6.9^{\circ}\end{array}$ \\
\hline Late blind & $\begin{array}{l}\text { Natural } \\
\text { Lightened }\end{array}$ & $\begin{array}{r}-3.6^{\circ} \\
2.3^{\circ} \\
\end{array}$ & $\begin{array}{l}4.8^{\circ} \\
6.9^{\circ} \\
\end{array}$ & $\begin{array}{r}-2.9^{\circ} \\
-2.7^{\circ} \\
\end{array}$ & $\begin{array}{r}9.3^{\circ} \\
5.8^{\circ} \\
\end{array}$ & $\begin{array}{l}0.5^{\circ} \\
1.2^{\circ} \\
\end{array}$ & $\begin{array}{l}4.0^{\circ} \\
5.1^{\circ} \\
\end{array}$ & $\begin{array}{l}1.5^{\circ} \\
3.8^{\circ} \\
\end{array}$ & $\begin{array}{l}11.7^{\circ} \\
11.4^{\circ}\end{array}$ \\
\hline
\end{tabular}

Note-Probabilities for $t$ tests are as follows: ${ }^{*} p<.05 ;{ }^{\dagger} .10>p>.05$.

preliminary analysis of variance (ANOVA) of signed errors showed that task/plane order (Task A/horizontal vs. Task B/frontal) and hand (left vs. right) had no effect and did not interact with any other factor (all $p s>.25$ ).

A 2 (visual status) $\times 2$ (task) $\times 4$ (orientation) ANOVA (with repeated measures on the two latter factors) of signed errors revealed no main effects of orientation $[F(3,66)=1, p>.25]$, visual status $[F(1,22)=0.04$, $p>.25]$, and task/plane $[F(1,22)=3.8, p=.062]$. The three-way orientation $X$ visual status $\times$ plane interaction was significant $[F(3,66)=4.3, p<.05]$. When decomposed, this interaction showed that in the frontal plane, the visual status $\times$ orientation interaction was significant $[F(3,66)=3.4, p<.05]$, but its meaning was not clear: Orientation did not significantly affect each visual status [early blind, $F(3,66)=2.2, p=.103$; late blind, $F(3,66)=1.4, p>.25]$, and visual status did not significantly affect the scores in each orientation [vertical, $F(1,22)=0.2, p>.25 ;+45^{\circ}, F(1,22)=2.1, p=.151$; horizontal, $F(1,22)=0.05, p>.25 ;+135^{\circ}, F(1,22)=$ $4.1, p>.05]$. In the horizontal plane, the visual status $\times$ orientation was not significant $[F(3,66)=1.5, p>.25]$. The other interactions were not significant: task/plane $X$ visual status $[F(1,22)=0.1, p>.25]$, orientation $\times$ visual status $[F(3,66)=0.6, p>.25]$, and orientation $\times$ task $[F(3,66)=0.6, p>.25]$.

In further $t$ tests, the mean values of each condition were compared with zero, in order to determine whether there were systematic directional errors. The results of these tests (Table 2) revealed no clear tendency and, except for one of them, they failed to reach significance. When the 32 conditions of this experiment were collapsed, the global mean error was positive $(M=0.86$, $S D=7.75)$ and not significant $[t(191)=1.53, p>.13]$. This suggests that, contrary to what was observed in the blindfolded sighted subject tested by Gentaz and Hatwell (1996b), the blind had no clear tendency to overshoot.

The mean absolute errors for each condition are shown in Table 3. Because absolute errors have generally an asymmetrical distribution, a logarithmic transformation $[\log (x+1)]$ was carried out on each angular difference in order to fulfill the normality condition required for the ANOVA. Table 3 indicates the mean absolute errors before transformation (in degrees) and after their $\log$ transformation. A preliminary ANOVA of absolute errors showed that task/plane order (Task A/horizontal vs. Task B/frontal) and hand (left vs. right) had no effect and did not interact with any other factor (all $p s>.25$ ).

A 2 (visual status) $\times 2$ (task) $\times 4$ (orientation) ANOVA (with repeated measures on the two latter factors) of absolute errors in log revealed a main effect of orientation $[F(3,66)=7.5, p<.001]$. Partial analyses showed no difference between the vertical $(M=0.84)$ and horizontal $(M=0.83)$ orientations $[F(1,22)=0.2, p>.25]$, nor between the $+45^{\circ}$ left $(M=0.97)$ and $+135^{\circ}$ right $(M=$ $0.98)$ obliques $[F(1,22)=0.06, p>.25]$. As is classically done in the literature, we collapsed the vertical and horizontal orientations on the one hand and the two oblique orientations on the other. This allowed preplanned measurement of the oblique effect. This effect (i.e., the difference between the magnitude of errors when setting vertical-horizontal and obliques) was significant $[F(1,22)=14.3, p<.01]$ : Errors were greater in the oblique $(M=0.97)$ than in the vertical-horizontal $(M=0.83)$ orientations. There was no main effect of visual status $[F(1,22)=0.5, p>.25]$ or task/plane $[F(1,22)=0.35, p>.25]$.

The orientation $\times$ task/plane interaction was significant $[F(3,66)=2.7, p<.05]$ (Figure 3 ), meaning that the oblique effect was not significant (vertical-horizontal, $\left.M=0.88 ; 45^{\circ}-135^{\circ}, M=0.95\right)$ in Task A/horizontal plane $[F(1,22)=2.4, p=.13]$ and was significant (vertical-horizontal, $M=0.78 ; 45^{\circ}-135^{\circ}, M=1$ ) in Task B/ frontal plane $[F(1,22)=23, p<.001]$. The task/plane factor did not affect the scores in the oblique settings $[F(1,22)=0.54, p>.25]$, whereas it approached significance in the vertical-horizontal settings $[F(1,22)=$ $3.83, p=.065]$ : errors were greater in the horizontal 
Table 3

Mean Absolute Angular Errors $(M$, in Degrees) and in $\log (x+1)$ and Standard Deviations of Means $(S D)$ as a Function of Plane, Visual Status, Forearm Condition, and Stimulus Orientation

\begin{tabular}{|c|c|c|c|c|c|c|c|c|c|}
\hline \multirow[b]{3}{*}{ Visual Status } & \multirow[b]{3}{*}{ Forearm } & \multicolumn{8}{|c|}{ Orientation } \\
\hline & & \multicolumn{2}{|c|}{ Vertical } & \multicolumn{2}{|c|}{$+45^{\circ}$} & \multicolumn{2}{|c|}{ Horizontal } & \multicolumn{2}{|c|}{$+135^{\circ}$} \\
\hline & & $M$ & $S D$ & $M$ & $S D$ & $M$ & $S D$ & $M$ & $S D$ \\
\hline \multicolumn{10}{|c|}{ Task A: Horizontal Plane } \\
\hline Early blind & $\begin{array}{l}\text { Unsupported } \\
\text { Supported }\end{array}$ & $\begin{array}{l}7.6^{\circ} \\
0.88 \\
9.5^{\circ} \\
0.94\end{array}$ & $\begin{array}{l}4.1^{\circ} \\
0.23 \\
6.9^{\circ} \\
0.28\end{array}$ & $\begin{array}{r}8.4^{\circ} \\
0.94 \\
13.6^{\circ} \\
1.14\end{array}$ & $\begin{array}{l}4.2^{\circ} \\
0.18 \\
5.1^{\circ} \\
0.17\end{array}$ & $\begin{array}{r}5.4^{\circ} \\
0.76 \\
11.6^{\circ} \\
1.01\end{array}$ & $\begin{array}{l}3.2^{\circ} \\
0.20 \\
3.7^{\circ} \\
0.14\end{array}$ & $\begin{array}{r}12.2^{\circ} \\
1.02 \\
10.1^{\circ} \\
0.99\end{array}$ & $\begin{array}{l}9.3^{\circ} \\
0.34 \\
5.1^{\circ} \\
0.24\end{array}$ \\
\hline Late blind & $\begin{array}{l}\text { Unsupported } \\
\text { Supported }\end{array}$ & $\begin{array}{l}8.7^{\circ} \\
0.93 \\
4.1^{\circ} \\
0.68\end{array}$ & $\begin{array}{l}5.5^{\circ} \\
0.25 \\
1.9^{\circ} \\
0.16\end{array}$ & $\begin{array}{r}7.5^{\circ} \\
0.77 \\
10.1^{\circ} \\
0.98\end{array}$ & $\begin{array}{l}7.3^{\circ} \\
0.45 \\
6.3^{\circ} \\
0.27\end{array}$ & $\begin{array}{l}7.8^{\circ} \\
0.90 \\
8.5^{\circ} \\
0.89\end{array}$ & $\begin{array}{l}3.7^{\circ} \\
0.25 \\
6.7^{\circ} \\
0.29\end{array}$ & $\begin{array}{l}9.2^{\circ} \\
0.83 \\
9.1^{\circ} \\
0.94\end{array}$ & $\begin{array}{l}7.3^{\circ} \\
0.51 \\
4.8^{\circ} \\
0.28\end{array}$ \\
\hline \multicolumn{10}{|c|}{ Task B: Frontal Plane } \\
\hline Early blind & $\begin{array}{l}\text { Natural } \\
\text { Lightened }\end{array}$ & $\begin{array}{l}5.0^{\circ} \\
0.77 \\
6.2^{\circ} \\
0.85\end{array}$ & $\begin{array}{l}1.4^{\circ} \\
0.11 \\
1.6^{\circ} \\
0.09\end{array}$ & $\begin{array}{r}7.8^{\circ} \\
0.92 \\
11.4^{\circ} \\
1.08\end{array}$ & $\begin{array}{l}3.4^{\circ} \\
0.15 \\
2.8^{\circ} \\
0.11\end{array}$ & $\begin{array}{l}4.0^{\circ} \\
0.65 \\
6.7^{\circ} \\
0.83\end{array}$ & $\begin{array}{l}2.7^{\circ} \\
0.22 \\
3.8^{\circ} \\
0.27\end{array}$ & $\begin{array}{l}8.5^{\circ} \\
0.93 \\
8.8^{\circ} \\
0.97\end{array}$ & $\begin{array}{l}4.7^{\circ} \\
0.25 \\
3.3^{\circ} \\
0.14\end{array}$ \\
\hline Late blind & $\begin{array}{l}\text { Natural } \\
\text { Lightened }\end{array}$ & $\begin{array}{l}5.2^{\circ} \\
0.76 \\
8.1^{\circ} \\
0.93\end{array}$ & $\begin{array}{l}2.7^{\circ} \\
0.19 \\
3.7^{\circ} \\
0.18\end{array}$ & $\begin{array}{r}10.3^{\circ} \\
1.02 \\
8.6^{\circ} \\
0.92\end{array}$ & $\begin{array}{l}5.5^{\circ} \\
0.20 \\
6.5^{\circ} \\
0.24\end{array}$ & $\begin{array}{l}5.2^{\circ} \\
0.76 \\
5.5^{\circ} \\
0.74\end{array}$ & $\begin{array}{l}2.7^{\circ} \\
0.19 \\
3.8^{\circ} \\
0.30\end{array}$ & $\begin{array}{r}9.7^{\circ} \\
0.97 \\
14.7^{\circ} \\
1.18\end{array}$ & $\begin{array}{l}5.6^{\circ} \\
0.26 \\
4.7^{\circ} \\
0.12\end{array}$ \\
\hline
\end{tabular}

Note- This table indicates the mean absolute errors before transformation (in degrees) and after their $\log (x+1)$ transformation. This transformation was carried out on each angular difference, and the mean of error was then calculated on these $\log (x+1)$ values.

plane $(M=0.88)$ than in the frontal plane $(M=0.78)$. The improvement in performance (absolute errors in log) was significant for the horizontal orientation [improvement in $0.17 ; F(1,22)=8, p<.05]$ and not significant for the vertical orientation [improvement in $0.04 ; F(1,22)$ $=0.2, p>.25]$. The other interactions were not significant: task/plane $\times$ visual status $[F(1,22)=2.3, p=.14]$, orientation $\times$ visual status $[F(3,66)=0.6, p>.25]$, and orientation $\times$ visual status $\times$ task/plane $[F(3,66)=0.4$, $p>.25]$.

\section{Horizontal Plane}

Another ANOVA was performed on absolute errors in $\log$ on Task A/horizontal plane only, in order to examine, in this task, the effect of forearm conditions (supported forearm vs. unsupported forearm). This 2 (visual status) $\times 2$ (forearm condition) $\times 4$ (orientation) ANOVA (with repeated measures on the last factor) revealed no main effect of orientation $[F(3,60)=0.85, p>.25]$, visual status $[F(1,20)=1.9, p=.192]$, or forearm condition $[F(1,20)=0.99, p>.25]$, nor was there an interaction between these factors: visual status $\times$ forearm condition $[F(1,20)=0.6, p>.25]$, orientation $\times$ visual status $[F(3,60)=0.35, p>.25]$, orientation $\times$ forearm condition $[F(3,60)=1.9, p=.144]$, orientation $\times$ visual status $\times$ forearm condition $[F(3,60)=1.4, p>.25]$.

\section{Frontal Plane}

A further ANOVA was performed on absolute errors in $\log$ on Task $B$ /frontal plane only, in order to examine, in this task, the effect of forearm conditions (natural vs. lightened). This 2 (visual status) $\times 2$ (forearm condition) $\times 4$ (orientation) ANOVA (with repeated measures on the last factor) revealed a main effect of orientation $[F(3,60)=13.9, p<.001]$. Partial analyses showed that the difference between the vertical $(M=0.82)$ and horizontal $(M=0.74)$ orientations failed to reach significance $[F(1,20)=4.3, p=.09]$, and that there was no difference between the $+45^{\circ}(M=0.99)$ and $+135^{\circ}(M=$ $1.0)$ obliques $[F(1,20)=0.33, p>.25]$. Although the difference between the vertical and horizontal orientations approached significance, we collapsed these values in order to measure the oblique effect. We also collapsed the two oblique orientations. The oblique effect was significant $[F(1,20)=23, p<.01]$ : Errors were higher in the oblique than in the vertical-horizontal orientations. Although nonsignificant, the main effect of forearm condition $[F(1,20)=2.7, p=.11]$ was in the same direction as it was in the blindfolded sighted subjects tested in Gentaz and Hatwell's (1996b) study-that is, lower global accuracy in the lightened condition $(M=$ $0.87)$ than in the natural condition $(M=0.78)$. The forearm condition $X$ orientation interaction was not significant $[F(3,60)=0.4, p>.25]$. The visual status effect was not significant $[F(1,20)=0.34, p>.25]$, and visual status did not interact with orientation $[F(3,60)=0.95$, $p>.25]$ or forearm condition $[F(1,20)=0.21, p>.25]$. The interaction of orientation, forearm condition, and visual status failed to reach significance $[F(3,60)=2.2$, $p=.094]$.

Finally, an additional ANOVA was performed on absolute errors in log with the gravitational cues as a within-group variable. On the one hand, the unsupported forearm condition of Task $A$ and the natural condition of 


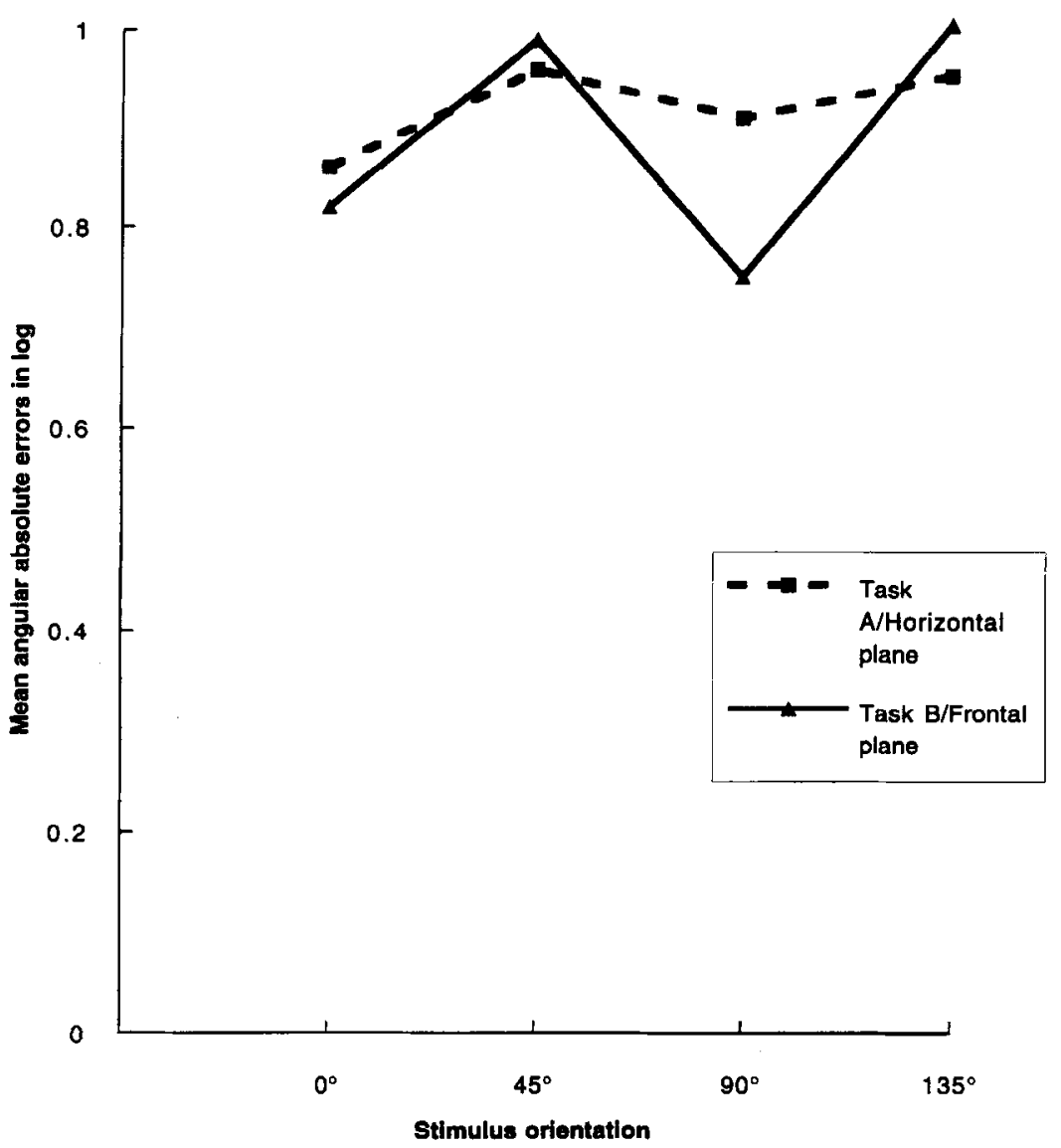

Figure 3. Mean absolute angular errors in $\log$ as a function of task/plane and stimulus orientation.

Task B were collapsed and labeled natural gravitational cues. On the other hand, the supported forearm condition of Task A and lightened forearm condition of Task B were collapsed and labeled reduced gravitational cues. This 2 (visual status) $\times 2$ (gravitational cues) $\times 4$ (orientation) ANOVA (with repeated measures on the two latter factors) revealed a main effect of orientation $[F(3,66)=7.5, p<.001]$. As stated previously, partial analyses showed that the oblique effect was significant $[F(1,22)=14.3, p<.01]$ : Errors were greater in the oblique $(M=0.97)$ than in the vertical-horizontal $(M=$ 0.83 ) orientations. There was no main effect of visual status $[F(1,22)=0.5, p>.25]$ or gravitational cues $[F(1,22)=0.02, p>.25]$. The interactions were not significant: gravitational cues $\times$ visual status $[F(1,22)=$ $0.14, p>.25]$, orientation $\times$ visual status $[F(3,66)=$ $0.6, p>.25]$, orientation $\times$ gravitational cues $[F(3,66)=$ $1.9, p=.133]$, and orientation $\times$ visual status $\times$ gravitational cues $[F(3,66)=1.2, p>.25]$.

All the analyses reported above were focused on the oblique effect (the difference between the accuracy of the vertical-horizontal settings and of the oblique settings) in order to determine whether the same pattern of results would be observed in the blind subjects tested here and the blindfolded sighted tested by Gentaz and Hatwell (1996b). Another question concerns the accuracy of the global performances of the two populations. Actually, the rate of global errors was higher in the blind subjects than in the blindfolded sighted subjects. But this comparison is not entirely legitimate, for two main reasons. First, the mean age was considerably higher for the blind subjects ( 38 years) than for the sighted subjects ( 20 years). Second, and more importantly, the level of education was different in the two populations. Whereas the blindfolded sighted subjects were university students, the blind subjects had attended only some college and they had then been integrated into workshops adapted for visually impaired adults. In these workshops, the blind subjects had an intense involvement in their work, but this work was generally repetitive. That is why we were interested only in the qualitative patterns of results of the blind (the haptic oblique effect) and not in the quantitative analysis of their global rate of accuracy.

\section{DISCUSSION}

In this research, we studied the role of visual experience in the haptic oblique effect in situations where the 
gravitational cues provided during scanning were varied. We hypothesized that if visual experience participated in the variations of this effect as a function of the availability of gravitational cues (as was the case in the blindfolded sighted subjects studied by Gentaz \& Hatwell, $1996 \mathrm{~b}$ ), the performances of late blind subjects should be similar to those of the blindfolded sighted subjects, whereas no oblique effect should be observed in early blind subjects. We tested these hypotheses by asking early and late blind subjects to reproduce vertical, horizontal, $+45^{\circ}$ oblique, and $+135^{\circ}$ oblique orientations in different planes (Task A/horizontal plane and Task B/ frontal plane) and in different forearm conditions of exploration: with reduced levels of $\mathrm{G}$ (supported forearm condition in Task $\mathrm{A} /$ horizontal plane and lightened forearm condition in Task $\mathrm{B} /$ frontal plane) or with natural level of $G$ (unsupported forearm condition in Task $\mathrm{A} /$ horizontal plane and normal control condition in Task B/frontal plane).

We shall first compare the early and late blind subjects. No differences in performance were found between these two groups, whatever the experimental conditions. In addition, contrary to the assumption that the oblique effect resulted from visual representations, we observed that late blind subjects did not manifest this effect in Task A (horizontal plane) and that early blind subjects manifested it in Task B (frontal plane). These results did not reveal any effect of visual experience on the haptic oblique effect. As was reported in the introduction, the performance of early blind subjects was generally found to be the same as that of late blind subjects in tabletop tasks involving simple reproduction of previously acquired spatial information (Klatzky et al., 1995; ThinusBlanc \& Gaunet, 1997). Because the tasks studied in the present research belong to this category, the absence of difference as a function of visual status is consistent with these observations.

Let us now examine the role of the plane in which the task was performed. In Task A (horizontal plane), the oblique effect was absent in the blind, whereas in Task B (frontal plane), this effect was present. It was due to a greater accuracy of the coding of the vertical-horizontal orientations than of the obliques, which did not vary according to the plane.

These results are different from those previously reported on blindfolded sighted subjects by Gentaz and Hatwell (1996b) in which the oblique effect was equally present in both planes. As stated earlier, the plane in which the task was performed modified the variability of gravitational cues. In the horizontal plane, the armhand system scanned always in a direction perpendicular to gravity, and the antigravitational forces required by scanning were therefore constant. As a result, variability was minimal. In this condition, the oblique effect was absent in blind subjects. By contrast, in the frontal plane, the antigravitational forces generated by scanning varied consistently as a function of the direction of exploration (upward or downward), and the oblique effect was pres- ent. Therefore, the variability of gravitational cues seems to be the main factor in the elicitation of the oblique effect in the blind.

Why, in the blind, would variability elicit or not elicit the oblique effect? A tentative explanation suggested by Gentaz and Hatwell (1996b) relies on the selection of the mode of coding, which may depend on the nature of the available gravitational cues. A high variability of these cues (in the frontal plane) would induce a spatial coding based on a Cartesian coordinate system and would therefore generate an oblique effect, whereas a low variability (in the horizontal plane) would induce a mode of coding based on movement and would not generate this oblique effect. The factor determining the selection of the mode of coding may rely on the cost of the processes involved in each one. The coding based on the Cartesian frame necessarily involves some spatial processing relating the inputs extracted from the currently explored region of the stimulus to the coordinate axes. These axes are very salient in the frontal plane, because of the gravitational cues specifying the gravity direction, and they are therefore easily accessible. In the horizontal plane, the vertical axis must be inferred from the gravitational vertical and projected horizontally. The coordinate axes are therefore less salient, and their spatial coding requires more cognitive effort. It may be that when our task was performed in the horizontal plane, the blind adults selected the more economic mode of coding on the basis of movement.

This assumption may be consistent with Millar's (1994) statement that the presence or absence of the oblique effect in haptics depends on the presence or $a b-$ sence of reference cues in the experimental conditions. It is also consistent with Heller, Calcaterra, Tyler, and Burson's (1996) study. These authors presented to early blind, late blind, and blindfolded sighted subjects a multiple-choice task which required the subjects to match tangible perspective drawings to a slanted board (horizontal, $-22.5^{\circ},-45^{\circ},-67.5^{\circ}$, and vertical). This task required the subjects to explore the board, thereby activating the arm-hand system. The results showed that the subjects were more accurate at the horizontal and vertical orientations than they were with other slants. In addition, both groups of blind subjects performed better than the blindfolded sighted subjects when the board was vertical - that is, when the variability of gravitational cues was high.

The effect of forearm condition was not significant in either Task A or Task B, and forearm condition did not interact with other factors. This is different from what was reported for blindfolded sighted subjects by Gentaz and Hatwell (1996b), who found that the oblique effect was absent or reduced when the gravitational cues were reduced (supported or lightened conditions) and was present when these cues were natural (unsupported and natural conditions).

Taken together, our results suggest that in both the blind subjects and the blindfolded sighted subjects the 
availability of gravitational cues affected the oblique effect. But although the general processing seems similar in the two populations (the oblique effect was generally due to a greater accuracy of the coding of the vertical-horizontal orientations in comparison with obliques), different parameters act according to visual status: magnitude of gravitational cues in blindfolded sighted subjects (Gentaz \& Hatwell, 1996b) versus variability of these cues in the blind.

In summary, in the present study we have shown, first, that the variability of gravitational cues during scanning was involved in the oblique effect in blind people. The oblique effect was present when the variability of these cues was high (in the frontal plane), and it was absent when the variability of these cues was minimal (in the horizontal plane). Second, the results did not reveal a significant effect of visual experience on the haptic oblique effect in a reproduction task of oriented rods: There was no difference in performance between the early blind and late blind adults.

\section{REFERENCES}

Appelle, S. (1972). Perception and discrimination as a function of stimulus orientation: The "oblique effect" in man and animals. Psychological Bulletin, 78, 266-278.

Appelle, S., \& Countryman, M. (1986). Eliminating the haptic oblique effect: Influence of scanning incongruity and prior knowledge of the standards. Perception, 15, 365-369.

APPELlE, S., \& GRAVETTER, F. (1985). Effect of modality-specific experience on visual and haptic judgement of orientation. Perception, 14, 763-773.

BERTHOZ, A. (1991). Reference frames for the perception and control of movement. In J. Paillard (Ed.), Brain and space (pp. 81-111). New York: Oxford University Press.

BRYANT, P. (1974). Perception and understanding in young children. New York: Basic Books.

CeCAla, A. J., \& GARNER, W. R. (1986). Internal frame of reference as a determinant of the oblique effect. Journal of Experimental Psychology: Human Perception \& Performance, 12, 314-323.

Chen, S., \& Levi, D. M. (1996). Meridional anisotropy in the discrimination of parallel and perpendicular lines - effect of body tilt. Perception, 25, 633-649.

Corballis, M. C., \& Beale, I. L. (1976). The psychology of the left and right. Hillsdale, $\mathrm{NJ}$ : Erlbaum.

DiCK, M., \& HochSTEIN, S. (1989). Visual orientation estimation. Perception \& Psychophysics, 46, 227-234.

DiETz, V. (1994). Neuronal basis of stance regulation: Interlimb coordination and antigravity receptor function. In S. Swinnen, $H$. Heuer, J. Massion, \& P. Casaer (Eds.), Interlimb coordination: Neural, dynamical and cognitive constraints (pp. 167-178). New York: Academic Press.

Essock, E. A. (1980). The oblique effect of stimulus identification considered with respect to two classes of oblique effects. Perception, 9 , 37-46.

Essock, E. A. (1990). The influence of stimulus length on the oblique effect of contrast sensitivity. Vision Research, 30, 1243-1246.

Gentaz, E., \& Hatwell, Y. (1994). L'effet de l'oblique [The "oblique effect"]. Pour la Science (French edition of Scientific American], 198, 20-21.

Gentaz, E., \& Hatwell, Y. (1995). The haptic "oblique effect" in children's and adults' perception of orientation. Perception, 24, 631-646.

GentaZ, E., \& Hatwell, Y. (1996a). Rôle du "travail d'exploration" dans la perception haptique (tactilo-kinesthésique) des orientations [Role of the "exploratory work" in the haptic perception of orientations]. In
F. Y. Doré (Ed.), Abstracts of the XXVI International Congress of Psychology (Vol. 31, p. 477). Montreal, Canada: Psychology Press. GeNTAZ, E., \& HATWELL, Y. (1996b). Role of gravitational cues in the haptic perception of orientation. Perception \& Psychophysics, 58, 1278-1292.

HATWELL, Y. (1978). Form perception and related issues in blind humans. In R. Held, H. W. Leibowitz, \& H. L. Teuber (Eds.), Handbook of sensory physiology: VII. Perception (pp. 489-519). New York: Springer-Verlag.

Hatwell, Y. (1985). Piagetian reasoning and the blind. New York: American Foundation for the Blind. [Original work published 1966: Privation sensorielle et intelligence. Paris: Presses Universitaires de France.]

HaTWELL, Y. (1990). Spatial perception by eye and hand: Comparison and intermodal integration. In C. Bard, M. Fleury, \& L. Hay (Eds.), Development of eye-hand coordination across life-span (pp. 99132). Columbia: University of South Carolina Press.

HATWELL, Y. (1994). Transferts intermodaux et intégration intermodale [Cross-modal transfer and cross-modal integration]. In M. Richelle, J. Requin, \& M. Robert (Eds.), Traité de Psychologie Expérimentale [Handbook of Experimental Psychology] (pp. 543-584). Paris: Presses Universitaires de France.

HeEley, D. W., \& Timmey, B. (1988). Meridional anisotropies of orientation discrimination for sine wave gratings. Vision Research, 28, 337-344.

HELLER, M. A. (1987). The effect of orientation on visual and tactual braille recognition. Perception, 16, 291-298.

Heller, M. A. (1989). Tactile memory in sighted and blind observers: The influence of orientation and rate of presentation. Perception, 18, 121-133.

Heller, M. A. (1991). Haptic perception in blind people. In M. A. Heller \& W. Schiff (Eds.), The psychology of touch (pp. 239-261). Hillsdale, NJ: Erlbaum.

HELLER, M. A. (1992). The effect of orientation on tactual braille recognition: Optimal touching positions. Perception \& Psychophysics, 51, 549-556.

Heller, M. A., Calcaterra, J. A., Burson, L. L., \& Tyler, L. A. (1996). Tactual picture identification by blind and sighted people: Effects of providing categorical information. Perception \& Psychophysics, 58, 310-323.

Heller, M. A., Calcaterra, J. A., Tyler, L. A., \& Burson, L. L. (1996). Production and interpretation of perspective drawings by blind and sighted people. Perception, 25, 321-334.

Heller, M. A., \& JoYner, T. D. (1993). Mechanisms in the haptic horizontal-vertical illusion: Evidence from sighted and blind subjects. Perception \& Psychophysics, 53, 422-428.

HelleR, M. A., \& SCHIFF, W. (1991). The psychology of touch. Hillsdale, NJ: Erlbaum.

Hermelin, B., \& O'ConNor, N. (1971). Spatial coding in normal, autistic and blind children. Perceptual \& Motor Skills, 33, 127-132.

Howard, I. P. (1982). Human visual orientation. New York: Wiley. JENKINS, B. (1985). Orientational anisotropy in the human visual system. Perception \& Psychophysics, 37, 125-134.

Klatzky, R. L., Golledge, R. G., Loomis, J. M., Cicinelli, J. G., \& Pellegrino, J. W. (1995). Performance of blind and sighted persons on spatial tasks. Journal of Visual Impairment \& Blindness, 89, 7082.

LASAGA, M. I., \& GARNER, W. R. (1983). Effect of line orientation on various information-processing tasks. Journal of Experimental Psychology: Human Perception \& Performance, 9, 215-225.

LECHELT, E. C. (1988). Spatial asymmetries in tactile discrimination of line orientation: A comparison of the sighted, visually impaired, and blind. Perception, 17, 579-585.

LeChelt, E. C., Eluuk, J., \& TANne, G. (1976). Perceptual orientational asymmetries: A comparison of visual and haptic space. Perception \& Psychophysics, 20, 463-469.

Lechelt, E. C., \& Verenka, A. (1980). Spatial anisotropy in intramodal and cross-modal judgements of stimulus orientations: The stability of the oblique effect. Perception, 9, 581-589.

Lederman, S. J., Klatzky, R. L., \& Barber, P. O. (1985). Spatial and 
movement-based heuristics for encoding pattern information through touch. Journal of Experimental Psychology: General, 114, 33-49.

LoNG, G. M., \& TuCK, J. P. (1991). Comparison of contrast sensitivity functions across three orientations: Implications for theory and testing. Perception, 20, 373-380.

Martinez, F. (1971). Comparison of two types of tactile exploration in a task of mirror-image recognition. Psychonomic Science, 22, 124125 .

MillaR, S. (1994). Understanding and representing space: Theory and evidence from studies with blind and sighted children. Oxford: Oxford University Press, Clarendon Press.

Paillard, J. (1991). Brain and space. New York: Oxford University Press.

PICK, H. L. (1974). Visual coding of non-visual spatial information. In R. B. MacLeod \& H. L. Pick (Eds.), Perception (pp. 153-165). Ithaca, NY: Cornell University Press.

POINTER, J. (1996). Evidence of a global oblique effect in human extrafoveal vision. Perception, 25, 523-530.

Rieser, J. J., \& PICK, H. L., JR. (1976). Reference systems and the perception of tactual and haptic orientation. Perception \& Psychophysics, 19, 117-121.

Ross, H. E. (1992). Orientation anisotropy: Some caveats in interpreting group differences and developmental changes. Ophthalmic \& Physiological Optics, 12, 215-219.

RosSetti, Y., Gaunet, F., \& Thinus-Blanc, C. (1996). Early visual experience affects memorization and spatial representations of proprioceptive targets. NeuroReport, 7, 1219-1223.

RosSETti, Y., \& RÉGNIER, C. (1995). Representations in action: Pointing to a target with various representations. In B. G. Bardy, R. J. Bootsma, \& Y. Guiard (Eds.), Studies in perception and action III (pp. 233-236). Mahwah, NJ: Erlbaum.

SAARINEN, J., \& LEVI, D. (1995). Orientation anisotropy in vernier acuity. Vision Research, 35, 2449-2461.

Stivalet, P., Marendaz, C., Barraclough, L., \& Mourareau, C. (1995). Effect of gravito-inertial cues on the coding of orientation in pre-attentive vision. Journal of Vestibular Research, 5, 125-135.

Thinus-Blanc, C., \& Gaunet, F. (1997). Representation of space in the blind: Vision as a spatial sense? Psychological Bulletin, 121, 20-42.

Vogels, R., \& Orban, G. A. (1985). The effect of practice on the oblique effect in line orientation judgements. Vision Research, 25, 1679-1687.

WorCHEL, P. (1951). Space perception and orientation in the blind. Psychological Monographs, 65 (No. 332).

YaKimofF, N., LánsKÝ, P., Mitrani, L., \& Radil, T. (1989). Is the $45^{\circ}$ oblique a third dominant direction? Acta Neurobiologiae Experimentalis, 49, 47-50.

(Manuscript received July 30, 1996; revision accepted for publication January 8, 1997.) 